most desperate means to obtain the drug which he knows will give him prompt and sure relief. Thus it becomes evident that all possibility of self-help is out of the question. Fear that he will suffer in the same way if he goes to an institution for treatment deters him from seeking remedial aid. How to cure these patients without suffering is, therefore, the most important factor in the problem. It has generally been considered impossible. I am convinced by years of experience in a sanatorium devoted to this specialty, that morphine can never be eliminated from an addict without suffering, if he is conscious, any more than his hand could be amputated without pain under similar circumstances. I therefore lay down the general principle that sleep solves the problem of the painless withdrawal of morphine as it has solved the problem of painless surgery. I have described this method of treating morphinism in other published papers. Briefly, it consists in keeping the patient asleep or in a somnolent state for a short time by the use of some of the hypnotic remedies that are familiar to all physicians. While the patient is thus somnolent the morphine is withdrawn. When he awakes the painful period is passed and all desire for morphine is gone. He then begins again to see clearly and to think normally. His outlook on life has entirely changed. Like John on Patmos, he beholds " a new heaven and a new earth." He begins once more to really live. While all this has been accomplished the patient has not suffered one minute of pain. The principle is the same as the administration of anæsthetics to obliterate the pain of a surgical operation. In carrying out this plan of treatment the physician's armamentarium should contain most of the hypnotic remedies, as no one remedy is sufficient. Among these hyoscine has been recommended, but I do not approve of it. It is a very uncertain, if not a dangerous, drug. For ten years I have been continuously using apomorphine in my sanatorium work for hypnotic purposes, and have found that in promptness and certainty of action it has no equal. While there are few infallible remedies, and this one may occasionally fail, yet among the hypnotics I know of none that is so certain in its effects. Its safety is another advantage. As one-tenth of a grain is universally considered a safe emetic dose, the hypnotic dose of one-thirtieth of a grain must be absolutely devoid of danger. The old gradual reduction method consists in reducing the size of the morphine dose daily till zero is reached. This means long-drawn-out misery for the patient as well as uncertain results. On the other hand, the method herein described is not only painless but sure. The after-treatment of morphinism is very important and should last several weeks. In addition to the products of the Pharmacopoia I find high-frequency electricity, mechanical vibration, light therapy, \&c., often of great value during this period.

To the resolution of the International Conference at Shanghai last February asking for international investigation regarding methods of treatment for the opium habit, I would make this reply: Morphinism can be cured surely, safely, and painlessly by a method that has been repeatedly used with all classes of patients under careful scientific observation. This method consists in artificially inducing the somnolent state during the withdrawal period.

$$
\text { I am, Sir, yours faithfully, }
$$

$$
\text { O. J. Douglas, M.D. }
$$

The Douglas Sanatorium, Dorchester, Mass., U.S.A., Sept. 20th, 1909

\section{RAT DESTRUCTION ON SHIPS.}

\section{Io the Editor of THE LANCET.}

SIR,-My attention has been called to the report in your issue of the 18th inst. on the Sixteenth International Medical Congress at Budapest in which, on p. 875, Dr. Belleli is reported to have said in the course of a discussion on the different methods employed for the destruction of rats in ships that "the Clayton gases damage several kinds of goods; silks are discoloured by it, tea loses its aroma, and cargoes of silk and tea are constantly arriving from the Far East, representing an enormous total value." of course, you give only a short summary of Dr. Belleli's remarks, but if Dr. Belleli declared without qualification that silks are discoloured and that tea loses its aroma when exposed to the action of the gas produced by my machine during the process of rat destruction on board ship, I can only say that he is very much misinformed. Numbers of vessels under all flags have had their rats destroyed with silk and tea in their holds without any damage whatever resulting to these goods. The silks, of course, are in bales, thoroughly protected by careful wrapping; the tea is in chests lined with tin-foil. I is very doubtful whether the gas penetrates the bales of silks, and still more questionable whether it passes through the tin-foil protecting the tea. But, in any case, the fact remains that no damage has ever resulted to such goods, and this can be attested by numerous firms in London and elsewhere who have had practical experien ce in the matter.

I am at Dr. Belleli's disposal to furnish him proofs of what I state and to give him facilities to carry out any experiments he desires, and I trust that you will give to this letter the same publicity as you have given to your correspondent's résumé of Dr. Belleli's remarks.

Paris, Sept. 22nd, 1909.

I am, Sir, yours faithfully,

T. A. Clayton.

\section{THE RECENT NAVAL COURT-MARTIAL.}

\section{To the Editor of THE LANCET.}

SIR,-All naval medical officers will approve of your note on the foolish proceedings taken at a court-martial against Fleet-Surgeon O. G. Matthew, but such a situation as is described should be impossible. It clearly resulted from the want of definite assignment of rank in the titles of naval medical officers. The commander could not have behaved so petulantly towards an officer whose rank was the equal of his own if that rank had been quite clearly marked in the title by which the fleet-surgeon was addressed. The title "Fleet-Surgeon" merely indicated to the commander an officer of seniority but of a subordinated branch. The title "Commander" would mark a man as an officer whom by instinct another commander would deal with as an equal. In the army the commander in this case would at his age have probably been a major and the fleet-surgeon a lieutenantcolonel, when such abuse of authority could never have occurred. If the Admiralty desire to prevent such occurrences in future they will attend to this lesson of the case. If rank, however, cannot be given, pay can, and increased pay generally secures increased consideration. If the Admiralty Committee on the Naval Medical Department cannot recommend more definite titular rank it should recommend material increase of pay to compensate for the obvious hardships which this case shows may lie before professional men who join the navy rather than the other military services of the State.

Sept. 25th, 1909.

I am, Sir, yours faithfully,

* * We doubt the value of our correspondent's proposal to obviate such occurrences by titular alterations.-ED. L.

Nursing in Montgomeryshire.-A scheme for the formation of a County Nursing Association was discussed at a largely attended meeting held at the Victoria Hall, Newton, Montgomeryshire, on Sept. 14th. Mr. David Davies, M.P., presided, and in his opening remarks pointed out that at the present moment no provision existed for nurses in rural districts in the county. Nursing associations had been formed, he believed, in connexion with every county in England. Wales, however, was very backward with regard to provision for nurses. Mr. C. E. Humphreys, medical officer for the county, said that the ideal nurse that was required for rural districts was a combination of district nurse and maternity nurse. A county nursing association ought to be able to supervise its nurses in the same way that midwives were supervised. With regard to the training of nurses, they should not go through a three years' course but a 10 or 12 months' course-four as maternity nurses and eight as district nurses. They would also act as health visitors to teach poor women the best way to feed and care for the children. The establishment of such a system of nursing throughout the country would have a great effect in diminishing the infantile mortality which at present stood very high. The Montgomery County Nursing Association was subsequently constituted, Mrs. Edward Davies being appointed president. The executive committee, consisting of 18 members, includes the names of Dr. Rees, Mr. W. E. L. Davies, Mr. R. D. Thomas, and Mr. N. W. Fairles-Humphreys. 